\title{
Specifics of Emergency Operation in Distribution Grid and their Effect on Integration and Functioning of Distributed Generation Facilities
}

\author{
P. V. Ilyushin ${ }^{1, *}$, A. L. Kulikov
}

\author{
${ }^{1}$ Energy Research Institute of the Russian Academy of Sciences, Moscow, Russia \\ ${ }^{2}$ R.E. Alekseev Nizhny Novgorod State Technical University, Russia
}

\begin{abstract}
This paper focuses on the characteristic features of distribution grids, which have the greatest impact on the stability of generators and motor loads. It shows that severe accidents in distribution and transmission grids differ in nature, starting with an overload leading to line disconnections and further evolving into a voltage collapse. It appears that where generator capacity is commensurate with the total power of motors in a grid, the motor load has a significant impact on transients. The paper discusses how asynchronous operation is triggered, progresses, and can be addressed in a grid with distributed generation (DG) facilities. It further analyzes the consequences of deep grid sectionalization and proves why grid structure needs to be optimized for further development. The paper also shows how to take into account the specifics of emergency processes (i.e., accident-associated processes) in distribution grids when integrating and operating DG facilities.
\end{abstract}

Index Terms: Distribution grid, emergency operation, distributed generation facilities, gas-turbine unit, steam-turbine unit, asynchronous operation, resynchronization, self-start, sectionalization.

\section{INTRODUCTION}

Over the past decade, the power industries in many countries (including Russia) have focused on measures lying in three key dimensions of development: decentralization, decarbonization, and digitalization.

This 3D approach stems from society's need for reasonably priced energy in required amounts, which

\footnotetext{
${ }^{*}$ Corresponding author.

E-mail: ilyushin.pv@mail.ru
}

http://dx.doi.org/10.38028/esr.2020.04.0001

Received November 06, 2020. Revised November 19, 2020.

Accepted December 13, 2020. Available online February 01, 2021.

This is an open access article under a Creative Commons Attribution-NonCommercial 4.0 International License.

(C) 2020 ESI SB RAS and authors. All rights reserved. is complicated by the necessity of delivering electricity reliably and safely.

Decentralization manifests itself through the adoption of an increasing number of distributed generation (DG) facilities, including renewable energy facilities (REF) that can be integrated into the power system or in islanded areas. Adding such facilities to the generator set alters substantially the transients [1-3].

Commissioning a DG facility enables its owner to deliver electricity to their power equipment reliably and independently; it also cuts energy costs, helping manufacture a cheaper-to-make and, therefore, more competitive product.

In the capacity range under consideration (several MW to several dozens MW), distributed generation is dominated by:

- gas-turbine power plants (GTPP) for the whole capacity range;

- gas-reciprocating power plants (GRPP) and diesel-fired power plants (DPP) at the lower end of the range;

- combined cycle gas-turbine plants (CCGTP), with gasturbine units (GTUs) providing most power [4].

Balanced use of conventional power plants and DG facilities in power systems makes such systems more durable and easier to control, intensifies regional economic development, and creates demand for innovation in power engineering $[5,6]$.

Integration of DG facilities is an efficient tool for optimizing the investment in upgrading the generating equipment employed at conventional power plants. In some cases, it is more cost-effective to commission DG facilities rather than to construct grid facilities to connect new customers. It is also recommendable to construct DG facilities instead of reconstructing grid facilities as long as the capacity of power transmission lines (PTL) and power transformers increases.

Notably, emergency operation is different in mediumand high-voltage distribution grids, and this needs to be borne in mind when integrating DG facilities. Let us analyze the specifics of such an operation and the limitations it imposes. 


\section{SPECIFICS OF DISTRIBUTION GRIDS}

There are several common factors descriptive of distribution grids. These are the factors that determine how transients progress in light of the significant variability of these parameters. The factors are:

- equivalent resistance values $\mathrm{x}_{\text {ext }}$ of interplant connections given in per-unit reduced to the baselines of the generators tested for stability $\left(S_{\text {bas }}=S_{\text {g.nom }}\right.$, $\left.U_{\text {bas }}=U_{\text {g.nom }}\right)$. Lower $\mathrm{x}_{\text {ext }}$, all other things being equal, stands for a more stable generator;

- the intensity of the load transient effect on generator transients. The load has the most profound impact when the motor slip considerably exceeds the critical value. The lower the resistance between the generator outputs and the busbars of electricity users, the greater the load-on-generator impact.

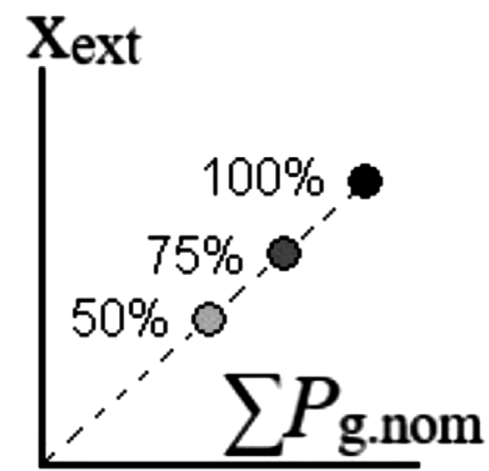

Fig. 1. $x_{\text {ext }}$ as affected by reducing the number of generators online.

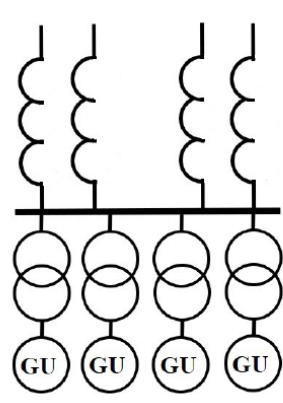

(a)

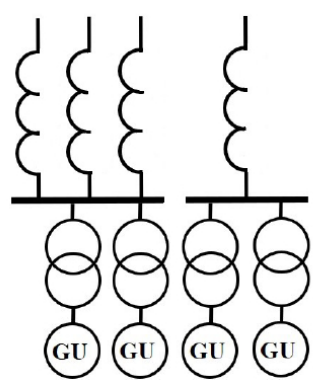

(c)

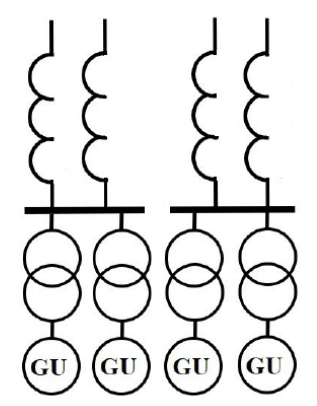

(b)

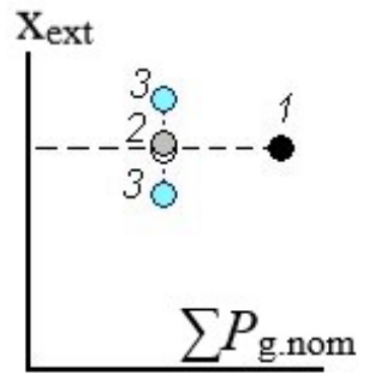

(d)
Fig. 2. $x_{\text {ext }}$ as affected by sectionalizing power plant busbars: (a)-(c) are the busbar sectionalization alternatives; (d) is the curve of $x_{\text {ext. }}$
For the first factor, it is important that reactance values xext follow a statistical pattern that shows: the higher is the capacity of the power plant, for which xext has been calculated, the higher are the reactance values. This is because the corresponding $\mathrm{Ohm}$ resistance values $\left(\mathrm{X}_{e x t}\right)$ depend on the grid density. The baseline resistance values are inversely proportional to the power plant capacity values

$$
Z_{\text {bas }}=U^{2}{ }_{\text {nom }} / \sum S_{\text {g.nom }} .
$$

Therefore, the relative resistance values $\mathrm{x}_{\text {ext }}=\mathrm{X}_{\text {ext }}$ / $Z_{\text {bas }}$ are on average proportional to $\sum S_{\text {g.nom }}$. Given that in addition to normal operation, the grid may be switched to one of several repair circuitries, and that the equipment currently online may vary in composition, it is the values $\mathrm{x}_{\text {ext }}=f\left(\sum \mathrm{P}_{\text {g.nom }}\right)$ that will correspond to the actual operating situations. Reducing the number of generators online will decrease $\sum \mathrm{P}_{\text {g.nom }}$ and $\mathrm{x}_{\text {ext }}$ (increasing $Z_{\text {bas }}$ ), see Fig. 1

When sectionalizing a distribution grid, each part of a power plant (a DG facility) needs to be analyzed individually. Switching from complete circuitry $2 a$ to sectionalized circuitry $2 b$ will not affect the value $\mathrm{x}_{\text {ext }}$, as it increases $\mathrm{X}_{e x t}$ and $Z_{b a s}$; in the case of the asymmetrical circuitry $2 c$ one of the values $\mathrm{x}_{\text {ext }}$ will drop, and the other one will rise, see Fig. $2 d$.

In transmission grids, xext values vary to a far greater extent compared to distribution grids, as the latter cover only small areas, where "weak cutsets" are usually not found. Since stability problems are mostly associated with such "weak cutsets", ensuring the dynamic stability of a distribution grid is less of an issue. Analysis of systemwide accidents and emergencies in distribution grids shows that they differ in nature from those in transmission grids [7-11].

As for the second factor, load transients are known to affect the dynamic stability of generators in distribution grids. If the generator capacity is commensurate with the total motor power at an industrial facility, or with the total power of another equipment cluster where the load is homogeneous, such a load will have an immense impact.

Consider the calculated transients in a $220-\mathrm{kV}$ distribution grid as caused by simultaneously disconnecting two power transmission lines that share the passage for over half the length of a shorter line, where the disconnection has been caused by a single-phase short circuit (SC) near a gasturbine power plant (GTPP) under commissioning. This causes a desynchronization (a pole slip), see Fig. $3 a$, which will be interrupted by the pole slip protection system (PSP).

Given that an SC-associated voltage sag will cause a substantial load-shedding (due to under-voltage protection, etc.), which will reduce the current drawn by the decelerating motors from the grid, the grid voltage will rise to prevent the GTPP generators from losing their dynamic stability, see Fig. $3 b[12,13]$.

Load transients affect generator stability in distribution grids to a greater extent compared to transmission grids for two reasons: 


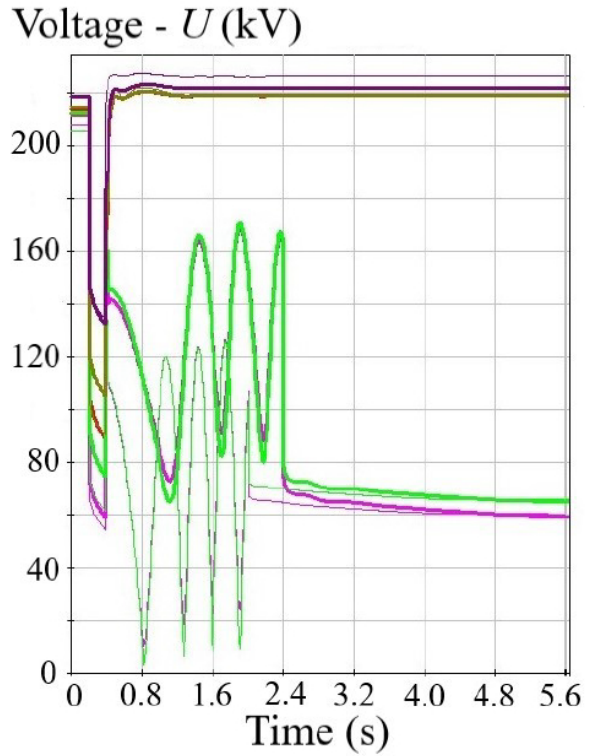

(a)

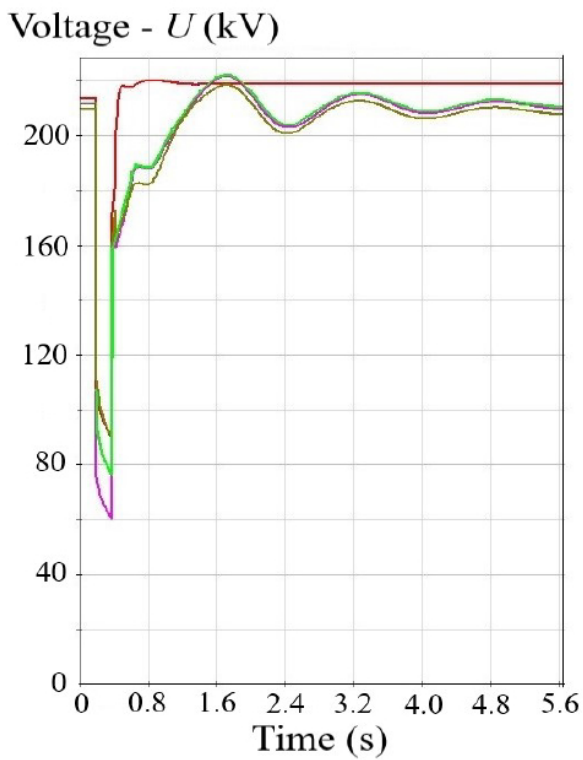

(b)

Fig. 3. Transient voltages in the case of a near-GTPP SC:

(a) the entire load is self-starting (thin lines mean the GTPP is offline, thick lines show the GTPP is online);

(b) $30 \%$ of the load is disconnected at $U<0.7$ Unom (the GTPP is online).

- a transmission grid disturbance will involve multiple customers' loads in the transient, thus leveling the effects of, and on, each of them;

- a transmission grid SC will tend to cause a far lesser voltage sag on the customers' busbars compared to a distribution grid SC due to the resistance of power transformers.

Therefore, when seeking to ensure the stability of generators at power plants in a distribution grid having DG facilities, one needs to take into account the properties of loads at the adjacent grid nodes. In practice, the use of calculation flowcharts that neither include nor are adjusted to the equations of induction motors at load nodes in most cases will produce wrong results $[14,15]$.

Let us analyze what consequences the above-mentioned specific features of distribution grids might have.

\section{ENSURING THE DYNAMIC STABILITY OF GENERATORS}

In the case of a failure to retain the dynamic stability of generators in a distribution grid, the voltage drop in the grid has a greater impact than the increase in the rotor angle against other generators $(\Delta \delta)$.

Excess in power transmitted through a weak cutset of the power system will violate the aperiodic static stability when such power $\mathrm{P}(\Delta \delta)$ peaks. Dynamic stability is similarly upset when the slip angle $(\Delta \delta)$ increases to such an extent that re-syncing becomes impossible.

In a transmission grid, when static stability is lost and generators switch to asynchronous operation, they may or may not cause a significant voltage drop on the power plant busbars, as the weak (or overloaded) cutset will

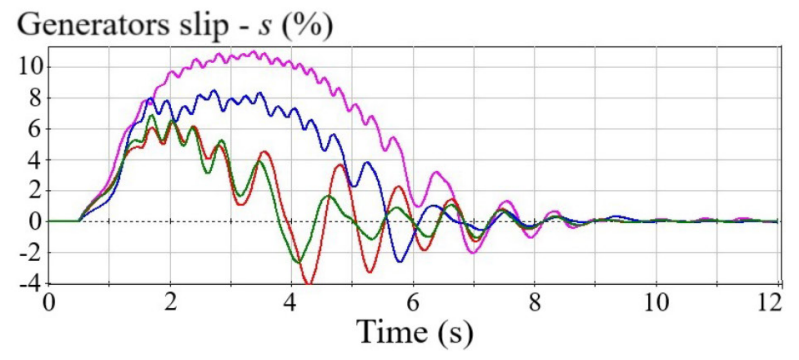

(a)

Voltage - $U$ (r.u.)

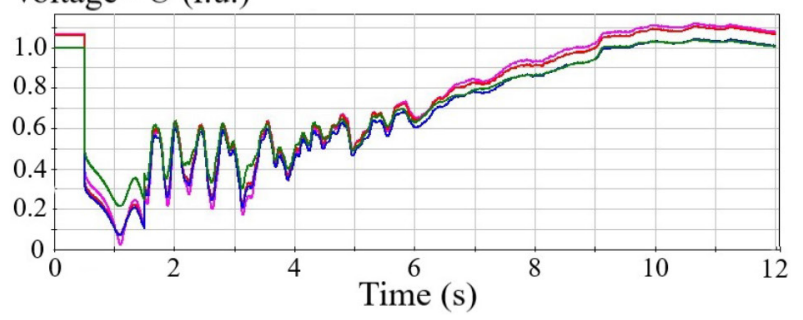

(b)

Motor speed - $n$ (r.u.)

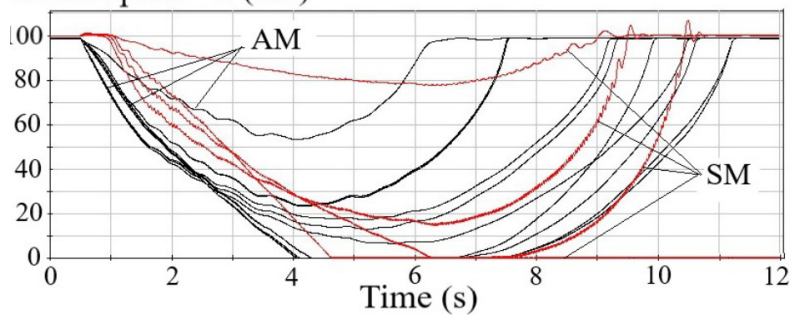

(c)

Fig. 4. Transient response to the de-syncing and re-syncing of $\mathrm{CHP}-1$ and $\mathrm{CHP}-2$ generators. 
carry the bulk of the equivalent resistance between the EMFs of the generators whose mutual stability has been disrupted.

In a distribution grid, where inter-generator equivalent resistances are low, loss of static stability by generators due to excessive power transmission through a cutset will only be possible if the grid overloads considerably exceed the permissible limits. For this reason, distribution grid destabilization first manifests itself as the overload of grid components.

In Phase I, the current load on the grid is growing while the node voltages are within the acceptable range. Power transmission lines are disconnected due to loads, whether the effects of the latter are direct or indirect. The

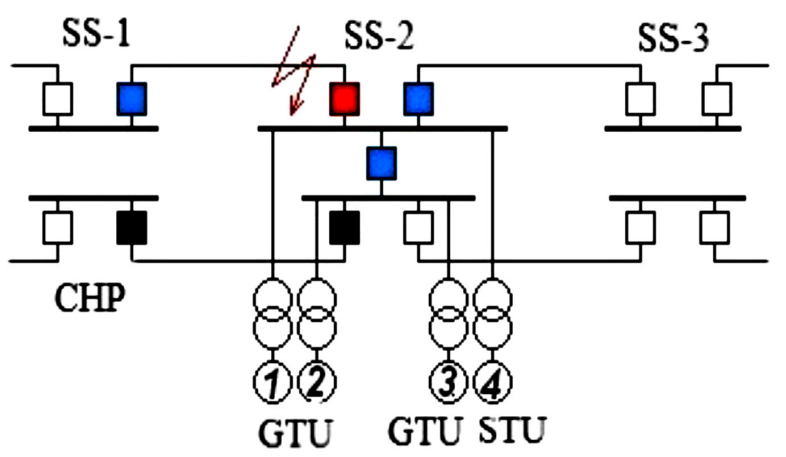

Fig. 5. Simplified single-line circuit diagram of a $110-\mathrm{kV}$ distribution grid fragment with CCGTP: red is for SC-induced circuit breaker failure; blue is for circuit breakers disconnected by the CBFP; black is for circuit breakers disconnected for PTL repair.

\section{Generators slip - $s(\%)$}

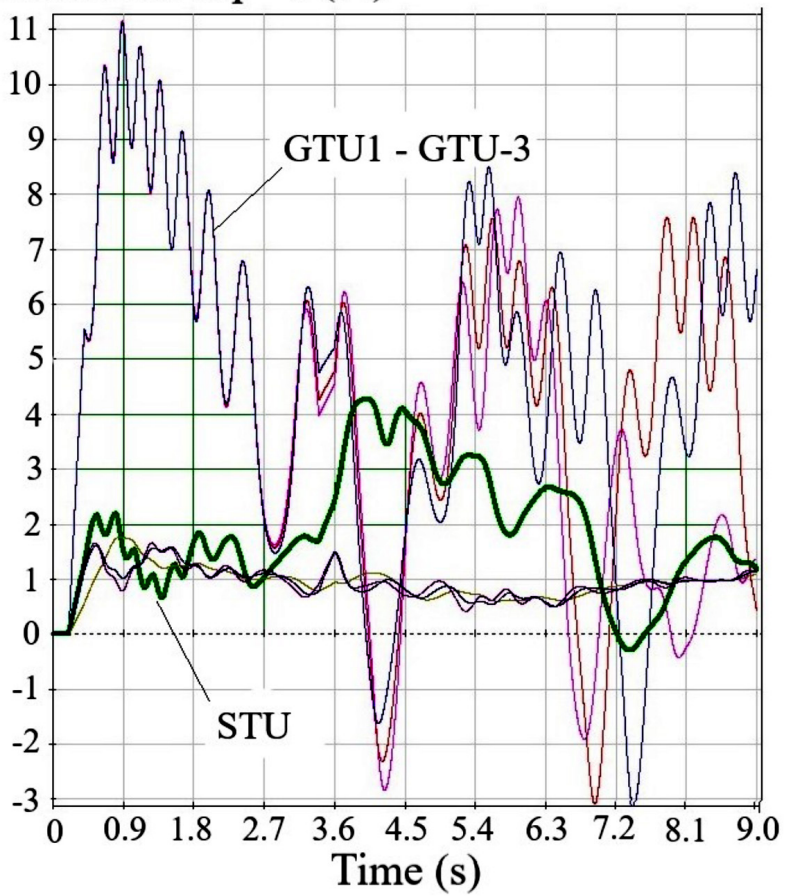

Fig. 6. Transient: short-term asynchronous operation due to a three-phase SC near the CCGTP. grid is weakened, which leads to further growth in current loads and more disconnections.

In Phase II, the voltage on the customer side drops so much that the customer needs to consume more reactive power, which leads to a further voltage sag and triggers a voltage collapse at the load nodes.

In this situation, the emergency is not caused by but results in generator destabilization, and the key factor here is the voltage sag on the customer side, which reduces their equivalent resistance to ground and increases the equivalent mutual inter-generator resistance, further increasing the angles $\Delta \delta$. Fig. 4 shows an example of such a process for a $110-\mathrm{kV}$ distribution grid.

In the transient shown in Fig. 4, a 1-second voltage sag in a $110-\mathrm{kV}$ grid cutset adjacent to CHP-1 and CHP-2 causes the loss of synchronism in CHP generators. Early in the transient, generator slips (Fig. 4a) develop at a relatively low rate, then such development accelerates due to a voltage sag, which, in turn, is caused by the deceleration of motors at the major industrial facilities nearby. Asynchronous operation ends when most of the motors self-start (some of the synchronous motors fail to do so).

Therefore, voltage closely links the transients (which determine the stability of generators in a distribution grid, including DG facilities) and the motor stability (self-starting).

\section{SPECIFICS OF ASYNCHRONOUS OPERATION IN DISTRIBUTION GRIDS}

Distribution grids contain multiple closely located medium- and low-capacity power plants, including DG facilities. As a result, SC-induced dynamic instability is usually localized and only affects a small segment of the grid.

Consider the asynchronous operating conditions at a combined cycle gas-turbine plant (CCGTP) comprised of three gas-turbine units (GTU) and a single steam-turbine unit (STU); let a three-phase SC on a 110-kV PTL running from the substation SS-2 cause a circuit breaker fault and trigger the circuit breaker failure protection (CBFP). Fig. 5 shows a simplified single-line diagram of a fragment of this $110-\mathrm{kV}$ distribution grid with the CCGTP.

Fig. 6 shows a short-term multi-machine asynchronous operation: transients in the GTUs and STU of the CCGTP are nearly independent due to the low $\mathrm{x}_{\text {ext }}$ values for this facility as compared to other power plants in the grid, as well as due to the high mutual resistance between the units.

The following segments can be seen in Fig. 6:

- at $0 \mathrm{~s}<t<3.5 \mathrm{~s}$, there is two-machine asynchronous operation as it involves the GTU cluster (GTUs 1 to 3 ) and the STU;

- at $4 \mathrm{~s}<t<4.5 \mathrm{~s}$, there is two-machine asynchronous operation as it involves the STU and the GTU cluster, although GTUs 1 to 3 are temporarily resynchronized within the cluster; 
- at $4.5 \mathrm{~s}<t<5 \mathrm{~s}$, there is two-machine asynchronous operation as it involves the GTU cluster and the STU;

- at $5 \mathrm{~s}<t<6.5 \mathrm{~s}$, there is multi-machine asynchronous operation, $f_{\text {GTU-1 to GTU-3 }}>f_{S T U}>f_{\text {grid }}$;

- at $t>7 \mathrm{~s}$, GTU-1 and the STU are resynchronized to each other, GTU-2 and GTU-3 are resynchronized as well, albeit only for a short time;

- at $t \approx 8 \mathrm{~s}$, three different frequencies can be observed simultaneously for a short time: $f_{\text {GTU-2 }}>f_{\text {GTU-3 }}>f_{\text {grid }}$.

In distribution grids, swing centers are rarely outside a power plant; in some cases, the swing center is near the generator outputs but more often within the stepup transformer. This is an immediate consequence of having many connections in a distribution grid at low relative resistances $\mathrm{x}_{\text {ext }}$. The chances that the generators will resynchronize themselves spontaneously are high, but so is the probability of the asynchronous operation evolving to affect multiple machines, which will prevent resynchronization (Fig.6) [16-18].

This is due to two factors:

- if there are multiple synchronous motors (SM) at a grid node, a generator slip at a nearby power plant will likely cause a loss of their synchronism as well (a visea-versa sequence is also possible);

- a multi-machine asynchronous operation may start if the same grid segment has STUs and GTUs with a free gas turbine. The mechanical constant of inertia is two to three times lower for the latter than for STUs or single-shaft GTUs. Loss of stability in a group of such generators will likely result in a multi-machine slip.

In transmission grids, slips are handled by separating the de-synced parts of the system; this happens so fast that secondary loss of stability does not occur.

The method is ineffective in the case of a distribution grid, as it quickly develops a multi-machine slip. Given that the swing center is near the generator, the PSPs will successfully disconnect it, even in the case of a multimachine asynchronous operation. In the event that the asynchronous operation involves desynchronized SMs, they must be disconnected to facilitate the selfresynchronization of generators.

\section{CONSEQUences of SeCtionalizing A Distribution GRID}

As loads increase in major cities and megacities, while opportunities for further grid development are limited, SC currents often tend to exceed the capacity of circuit breakers. For instance, SC currents would exceed $120 \mathrm{kA}$ in Moscow in the case of retaining a normal grid circuitry, which is twice the switching capacity of circuit breakers $(63 \mathrm{kA})$. Today and in the near future, the most practical SC-limiting solutions for 110 - to $220-\mathrm{kV}$ grids are:

\section{A. Uncontrolled current-limiting reactors (CLR)}

This is the easiest method; however, the voltage regulation and stability requirements, especially for substations at the end of a dead-end feeder, mean that it is unacceptable to have a significant CLR resistance. On the other hand, too many CLRs would be needed if their resistance were low (1 to $4 \mathrm{Ohm}$ ).

\section{B. Controlled current limiters (CL)}

These devices are capable of an inertia-free firstapproximation increase in their inductance by a factor of dozens to hundreds, with the restoration to normal operation, once the SC has been cleared. Whether it is a CL or a CLR, such units are difficult to install at an existing substation.

\section{Grid Sectionalization}

SC currents are the highest at substations where the SC current is contributed to by multiple sources: power plants or transmission grid coupling transformers. As some circuit breakers are disconnected, this contribution will be less and the total SC current will be reduced.

Bus-section circuit breakers are the most effective and safest to disconnect from the standpoint of grid reliability.

As of today, sectionalizing $110-$ to $220-\mathrm{kV}$ distribution grids is a necessary and common measure. Sectionalizing weakens the grid and makes electricity delivery less reliable. The practice has shown that a sufficiently extensive

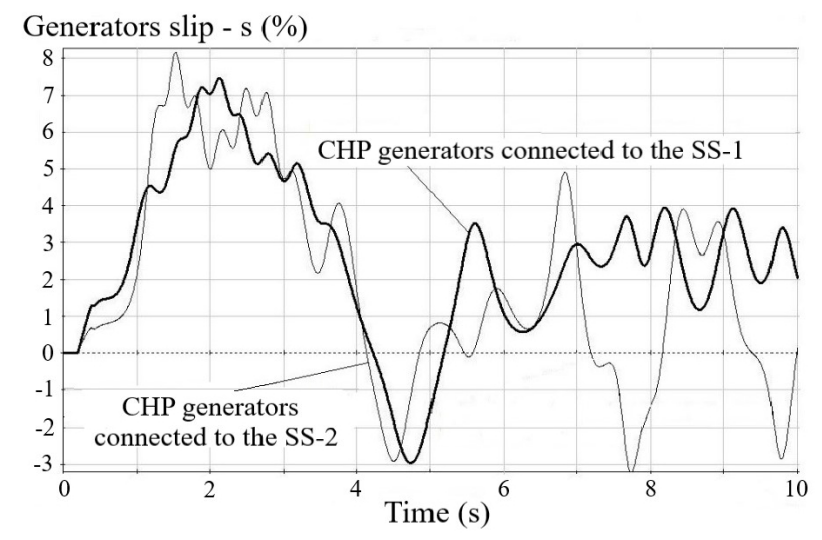

(a)

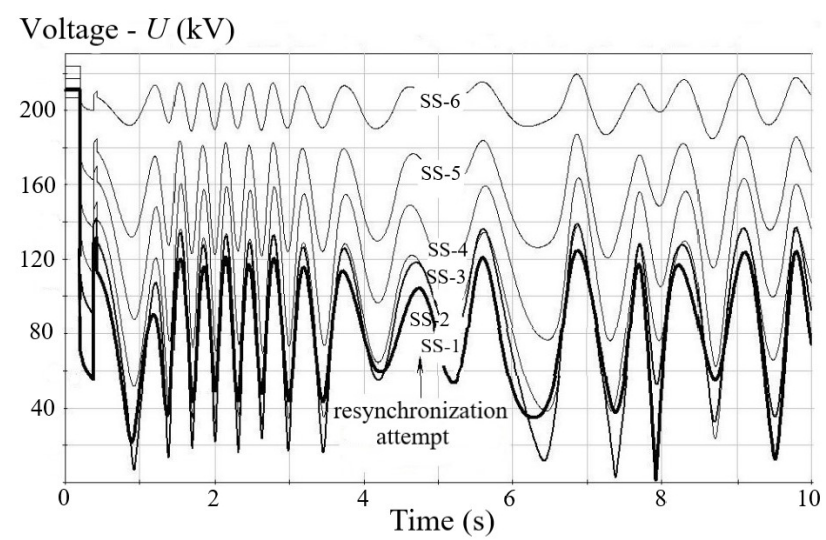

(b)

Fig. 7. Transient response to a two-phase ground fault in an extensively sectionalized grid: (a) generator slips at SS-1 and SS-2; (b) busbar voltages at the adjacent SSs. 
sectionalization prevents immediate severe consequences. Sectionalization opportunities are limited by grid controllability; besides, this effort needs to be continued whenever more power plants and customers are connected.

Consider a $220-\mathrm{kV}$ distribution grid, the extensive sectionalization of which has had a negative impact on the dynamic stability of power plant generators. Fig. 7 shows a transient caused by a two-phase ground fault in a $220-\mathrm{kV}$ PTL, causing an SS-1 circuit breaker failure and triggering the CBFP.

Fig. 7 shows a transient, where at $t \approx 4.3 \mathrm{~s}$ the system attempts to re-sync the generators of the CHP; however, the attempt fails, as motors at the adjacent nodes decelerate due to low voltage.

A series of transient calculations shows that the severity of the SC consequences depends not on the initial generator power shedding, which would depend on the SC type, but on the post-emergency condition of the grid, which in the case of three-phase rather than phase-by-phase circuit breaker control does not depend on the SC type.

A CL installed at SS-1 in series with the bus section circuit breaker would enable switching the circuit breakers on in the adjacent $220-\mathrm{kV}$ grid, and the transient would develop absolutely differently (Fig.8).

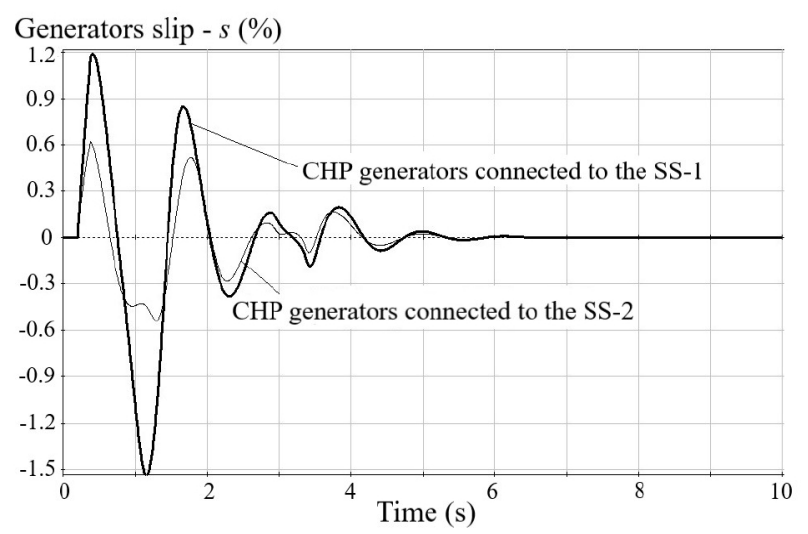

(a)

Voltage - $U(\mathrm{kV})$

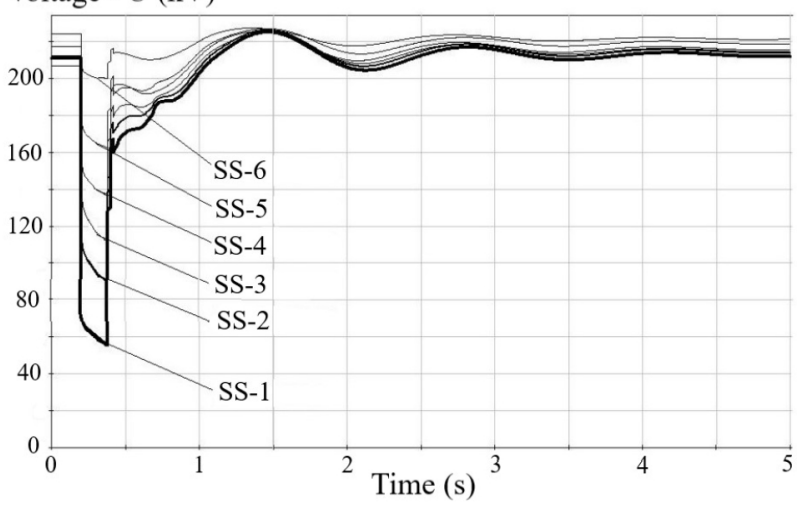

(b)

Fig. 8. Transient response to a two-phase ground fault with a CL at SS-1: (a) generator slips at SS-1 and SS-2; (b) busbar voltages at the adjacent SSS.
The transient shown in Fig. 8 does not cause secondary destabilization; motors at the load nodes restart quickly and without difficulty.

Therefore, if an emergency in a weakened (extensively sectionalized) grid develops slowly, the corresponding segment must be de-sectionalized to reduce the load to be disconnected, thus mitigating the negative impact of sectionalization.

However, if the emergency develops quickly as shown in Fig. 7, load shedding becomes necessary to avoid a voltage collapse; in that case, the amount of load to be shed by the relay protection and emergency control system will proportionately depend on the extent to which the grid is sectionalized [19-22].

As of today, opportunities for sectionalization that reduces SC currents but also weakens the grid have been nearly depleted, which calls for research of urban grid development to optimize the structure of such grids so that they could function reliably while reducing the SC currents.

\section{SPECIFICS OF Distributed GeNeration FaCILITIES}

Loads to be carried by the grids in major cities and megacities are rising, as many more customers are being newly connected, especially at the locations of comprehensive and infill development. The overloads occur in the PTLs, whether overhead or cable, as well as in power transformers at substations.

To address this issue, distributed generation facilities need to be constructed and connected to the existing distribution grids. They should be configured to concentrate the installed capacity in a small area so as to avoid overloading the distribution grid with transit power flows.

With respect to the reliability of electricity supply, the connection of DG facilities featuring low- and mediumcapacity generator sets is an effort that requires due attention to its specifics, and here is why:

- generator-to-grid connection resistance varies broadly; - in the case of a power system accident, islanding DG facilities to deliver electricity to the nearest customers might be problematic.

The DG operation practice shows that using nonselectively protected generator sets, i.e., the manufacturer's default protection settings, makes sense if the DG facility is connected to a "rigid" grid with the sole purpose of minimizing energy costs, where reliability is not a concern.

If the purpose of constructing a DG facility is to normalize the operating parameters of a weak or overloaded grid segment, the use of non-selectively protected generator sets to provide backup power to a variety of customers is not an acceptable solution.

Therefore, when designing a DG facility connection, one needs to determine whether the selected generator sets are well-compatible with the electricity delivery and consumption parameters, and the operating parameters of the distribution grid under consideration; and take into 
account the costs of commissioning/upgrading power equipment and secondary equipment (relay protection, emergency control systems, process protections, and automatic devices).

\section{CONCLUSION}

Distribution grids contain multiple closely located medium- and low-capacity power plants. As a result, SCinduced losses of dynamic stability are usually localized and only affect a small grid segment.

Unlike the most severe emergencies in transmission grids, those in distribution grids usually begin when PTLs are overloaded and disconnected sequentially, followed by a voltage collapse and loss of stability in generator/motor.

Distribution grids are at risk of loss of synchronism when exposed to an accident-associated (emergency) disturbance, especially if some generator sets have low mechanical constants of inertia; these asynchronous operating conditions might involve multiple machines, although generators may resynchronize spontaneously as well.

At low- and medium-capacity power plants, the swing center is usually near the generator outputs or in the stepup transformer.

Opportunities have been nearly depleted for sectionalization that reduces SC currents but also weakens the grid, which calls for research of urban grid development to optimize the structure of such grids so that they could function reliably while reducing the SC currents.

When designing a DG facility connection, one needs to determine whether the selected generator sets are wellcompatible with the electricity delivery and consumption parameters, and the operating parameters of the distribution grid under consideration. The costs of commissioning (upgrading) power equipment and secondary equipment (relay protection, emergency control systems, process protections, and automatic devices) must also be taken into account.

\section{REFERENCES}

[1] N. I. Voropai, "Multi-criteria problems in electric power system expansion planning," Energy Systems Research, vol. 1, is. 2, pp. 27-34, 2018.

[2] Z. Li, G. Yao, G. Geng, and Q. Jiang, "An efficient optimal control method for open-loop transient stability emergency control," IEEE Transactions on Power Systems, vol. 32, is. 4, pp. 2704-2713, 2017.

[3] A. Wen, M. Y. Zhao, W. F. Huang, and C. Z. Wei, "Design and development of wide-area protection and emergency control for application in distribution networks of embedded generation," Proceedings of the IEEE Power \& Energy Society General Meeting, pp. 1-5, 2015.

[4] G. M. Tina, S. Licciardello, and D. Stefanelli, "Conventional techniques for improving emergency control of transient stability in renewable-based power systems," Proceedings of the 9th Int. Renewable Energy Congress, 2018.
[5] Th. L. Vu and K. Turitsyn, "Options for emergency control of power grids with high penetration of renewables," Proceedings of the IEEE Int. Conf. on Sustainable Energy Technologies, 2016.

[6] R. Zhang, X. Lin, P. Yang, and Z. Li, "The emergency control strategies of a short-run isolated island wind farm," Proceedings of the Int. Conf. on Renewable Energy Research and Application, pp. 203-211, 2014.

[7] P. V. Ilyushin, A. L. Kulikov, "Adaptive algorithm for automated undervoltage protection of industrial power districts with distributed generation facilities," Proceedings of International Russian Automation Conference, 2019.

[8] Sk. R. Islam, D. Sutanto, and K. M. Muttaqi, "Coordinated decentralized emergency voltage and reactive power control to prevent long-term voltage instability in a power system," IEEE Transactions on Power Systems, vol. 30, is. 5, pp. 2591-2603, 2015.

[9] N. I. Voropai, V. A. Stennikov, B. Zhou, E. A. Barakhtenko, D. N. Karamov, O. N. Voitov, D. V. Sokolov, "An approach to the modeling of decentralized integrated energy systems with renewable energy sources," Energy Systems Research, vol. 2, is. 1, pp. 5-12, 2019.

[10] N. I. Voropai, "General methodological approaches to hierarchical modeling of complex systems," Energy Systems Research, vol. 2, is. 4, pp. 17-21, 2019.

[11] S. I. Budi, A. Nurdiansyah, and A. Lomi, "Impact of load shedding on frequency and voltage system," Proceedings of the Int. Sem. on Intelligent Technology and Its Applications, 2017.

[12] K. B. Kilani, M. Elleuch, and A. H. Hamida, "Dynamic under frequency load shedding in power systems," Proceedings of the 14th Int. Multi-Conf. on Systems, Signals, and Devices, 2017.

[13] Ya. L. Artsishevskiy and B. M. Gieev, "Adaptation of UFLS to a variable level of responsibility of $0.4 \mathrm{kV}$ electric receivers," Power engineer, vol. 5, pp. 18-21, 2017.

[14] A. L. Kulikov, M. V. Sharygin, P. V. Ilyushin, "Principles of organization of relay protection in microgrids with distributed power generation sources," Power Technology and Engineering, vol. 53, is. 5, pp. 611-617, 2020.

[15] A. L. Kulikov, D. I. Bezdushniy, M. V. Sharygin, and V. Yu. Osokin, "Analysis of the support vector machine implementation in the multi-dimensional relay protection," Izvestia RAN. Energetika, no. 2, pp. 123-132, 2020. (in Russian)

[16] P. V. Ilyushin, "Emergency and post-emergency control in the formation of micro-grids," Proceedings of Methodological Problems in Reliability Study of Large Energy Systems, vol. 25, 2017.

[17] P. V. Ilyushin, O. A. Sukhanov, "The structure of emergency-management systems of distribution networks in large cities," Russian Electrical Engineering, vol. 85, is. 3, pp. 133-137, 2014. 


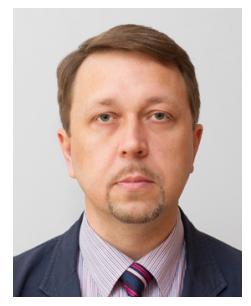

Pavel V. Ilyushin is chief researcher, head of the center "Intelligent Power Systems and Distributed Generation" of the Energy Research Institute of the Russian Academy of Sciences. P.V. Ilyushin graduated from Novosibirsk State Technical University in 1997. In 2020, he received his D.Sc. degree from the Scientific and Technical Center of the Federal Grid Company of the Unified Energy System. He is a chairman of SC C6 in the CIGRE Russian national committee. His research interests include distributed generation and distribution grids, power system automation.

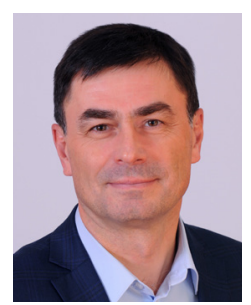

Alexander L. Kulikov is a professor at the Department of Power Engineering, Power Supply and Power Electronics of Nizhny Novgorod State Technical University named after R.E. Alekseev. A.L. Kulikov graduated from the Military Radio Engineering Academy of Air Defense named after Govorov L.A. in 1992. In 2007, he received his D.Sc. degree from V.I.Lenin Ivanovo State Power Engineering University. His research interests are relay protection, fault location, and digital signal processing. 